\title{
Biophysical Characteristics of Melasma Skin Comparing with the Perilesional Normal Skin and its Relation to the Melasma Subtype
}

\author{
Rahrovan $\mathbf{S}^{1}$, Hasanzadeh $\mathrm{H}^{2}$, Khodakarim $\mathbf{S}^{1}$ and Firooz $\mathrm{A}^{2, *}$ \\ ${ }^{1}$ School of Public Health, Shahid Beheshti University of Medical Sciences, Tehran, Iran \\ ${ }^{2}$ Center for Research and Training in Skin Diseases and Leprosy, Tehran University of Medical Sciences, Tehran, Iran
}

"Corresponding author: Alireza Firooz, Center for Research and Training in Skin Diseases and Leprosy, Tehran University of Medical Sciences, Tehran, Iran, Tel: +982188978190; E-mail: firozali@sina.tums.ac.ir

Rec date: September 30, 2015; Acc date: November 02, 2015; Pub date: November 10, 2015

Copyright: $\odot 2015$ Rahrovan, et al. This is an open-access article distributed under the terms of the Creative Commons Attribution License, which permits unrestricted use, distribution, and reproduction in any medium, provided the original author and source are credited.

\begin{abstract}
Background: Melasma is a common disorder of hyperpigmentation affecting millions of people worldwide. All the exact pathways to understand the complete pathogenesis of melasma is unknown.
\end{abstract}

Aims: To determine the biophysical characteristics of melasma skin compared to the normal surrounding skin.

Methods: Thirty-six patients with melasma were recruited in this case-control study. The subtype of melasma (epidermal, dermal, or mixed) was determined by Wood lamp examination. The melanin index, erythema index, stratum corneum (SC), hydration, sebum content, transepidermal water loss (TEWL), temperature, friction index, and $\mathrm{pH}$ of lesional and perilesional normal skin of patients were measured in standardized temperature and humidity conditions. The epidermal and dermal thickness and dermal echo-density were determined on the same locations. The measurements were compared between lesional and perilesional normal skin using dependent t-test and among three subtypes of melasma using one-way ANOVA. P values of $<0.05$ were considered statistically significant.

Results: Melanin index, erythema index, SC hydration, $\mathrm{pH}$, thickness of dermis and epidermis were significantly higher and the temperature was significantly lower in lesional skin compared with surrounding normal skin. No significant differences were found in TEWL, friction index, sebum content and density of dermis. Melasma subtype, age, skintype, location and duration of melasma had no significant effect on any of these variables.

Conclusions: Melasma skin is characterized by certain changes in biophysical factors of epidermis and dermis. The relation of these changes with the hyper-activity of melanocytes and melanin overproduction should be determined in future studies.

Keywords: Melasma; Melanin; Skin; Biophysical characteristics; Dermis; Epidermis

\section{Introduction}

Melasma is a common disorder of hyperpigmentation affecting millions of people around the world [1]. Four types of melasma are defined on the basis of Wood's light (320-400 nm) examination: epidermal type, dermal type, mixed type, and a fourth type, described in patients with dark skin [2].

The exact pathogenesis of the disorder is unclear, but some of etiologic agents have been signified. These include ultraviolet radiation, hormonal intermittence for example during pregnancy, thyroid dysfunction, and phototoxic and anti-seizure drugs [3]. Genetic background is also a classical influencing factor [4]. Approximately half of the patients had a familial history of melisma [4].

There are biologically active melanocytes in melasma skin, rather than an increase in melanocytes. [5]. A vascular component may also have a role in the pathogenesis of melasma [5]. Lesional skin had more numerous and larger blood vessels compared to normal skin [5].
The interaction of keratinocytes may also be involved in melasma: the activation of inducible nitric oxide synthase (iNOS) within keratinocytes particularly after ultraviolet (UV) radiation, has a role in melanogenesis process [4].

There is destruction in the basal membrane and collagen, which could enhance the fall of melanin and the migration of active melanocytes into the dermis allowing the constant hyperpigmentation in melisma [6]. Dermal fibroblasts possibly secrete a soluble form of SCF during inflammation, and with their c-kit receptor, they would cause hyperpigmentation in melasma; [6] also, the vascular endothelial growth factor, an important regulator of angiogenesis, is expressed by the endothelium in melisma [6].

A previous study compared the biophysical characteristics of melasma with normal adjacent skin in Asian patients and showed melanin index, erythema index, and SC hydration were significantly higher in melasma skin [7].

The objective of this study was to compare the biophysical properties of melasma skin with adjacent normal skin in another population, and to compare these parameters among different subtypes of melasma. 
Citation: Rahrovan S, Hasanzadeh H, Khodakarim S, Firooz A (2015) Biophysical Characteristics of Melasma Skin Comparing with the Perilesional Normal Skin and its Relation to the Melasma Subtype. Pigmentary Disorders 2: 222. doi:10.4172/2376-0427.1000222

Page 2 of 4

\section{Materials and Methods}

The study was performed in accordance with the Declaration of Helsinki of the World Medical Association and all patients signed an informed consent form for this investigation.

\section{Subjects}

Thirty-six non-pregnant female Iranian volunteers with melasma (11 epidermal, 12 mixed, and 13 dermal melasma subtypes based on Wood lamp examination) were recruited. Mean patient age was 37.97 \pm 6.66 years (27-55 years). Their skin phototypes were 3 or 4 Fitzpatrick skin type. Topical bleaching agents for 4 weeks and laser therapy, peeling or dermabrasion for 3 months prior to start day of the study were banned. The patients were allowed to use their routine sunscreen. They avoided skin care products on the measured sites during the 24 hour prior to measurements, and measured sites were not washed with surfactant within 0.5 hour of measurements. A spot with darkest pigmentation and a spot with no pigmentation closest to the first spot (as control normal skin) were selected for measurements.

\section{Measurements}

Melanin index, erythema index, SC hydration capacitances, TEWL, amounts of sebum, temperature, friction index and $\mathrm{pH}$ were determined for lesional and perilesional normal skin using appropriate probes (Mexameter: MX18; Corneometer: CM825; Tewameter: TM300; Sebumeter: SM815; Skin-Thermo-Meter ST 500; Frictiometer: FR700 and Skin-pH-Meter: PH 905) connected to a MPA 580 device (Courage + Khazaka electronic GmbH, Cologne, Germany).

Epidermal and dermal thickness and dermal density were also measured by high frequency ultrasonography (HFUS) on lesional and perilesional normal skin, using probes 22 and $50 \mathrm{MHz}$ (DUB ${ }^{\circ}$ skinscanner tpm;, Germany).

The environmental conditions for measurements were controlled at an ambient temperature of $25 \pm 2^{\circ} \mathrm{C}$ and a relative humidity of $30 \pm$ $5 \%$. The patients acclimated to these conditions for 20 minutes prior to measurements.

\section{Statistical analysis}

SPSS version 18.0 was used for statistical analysis. The normality of quantitative variables was checked with Kolmogorov-Smirnov test. Differences between lesional and perilesional normal skin for 11 biophysical variables (Diffs) had normal distribution so dependent $\mathrm{t}$ test was used to determine the significance of them (11 biophysical variables are: erythema, melanin, hydration, TEWL, sebum, temperature, friction, $\mathrm{pH}$, dermal thickness, dermal density and epidermal thickness).

Pearson correlation coefficient was used for evaluating the relation between age and Diffs; One-way ANOVA for duration and Diffs; Dependent $\mathrm{T}$ Test for location and Diffs; Independent $\mathrm{T}$ Test for skin type and Diffs, and one-way ANOVA for melasma subtype and Diffs.

Regression lineal model was used for evaluating the synchronous effect of age and skin type and melasma subtype and duration and location on Diffs.

$P$ values of $<0.05$ were considered statistically significant.

\section{Results}

Melanin index, erythema index, SC hydration, $\mathrm{pH}$, thickness of dermis and epidermis were significantly higher and the temperature was significantly lower in lesional skin than in perilesional normal skin (Figure 1).

Mean melanin index was higher in lesional than in perilesional normal skin $(234.66 \pm 47.91$ vs. $192.12 \pm 43.19, \mathrm{P}<0.001)$, as was mean erythema index $(399.18 \pm 83.95$ vs. $339.13 \pm 70.35, \mathrm{P}<0.001)$. Mean SC hydration $(58.85 \pm 11.46$ vs. $53.54 \pm 15.49 ; \mathrm{P}=0.037)$ and mean skin $\mathrm{pH}(5.55 \pm 0.57$ vs. $5.36 \pm 0.61, \mathrm{P}=0.002)$ were also higher.

No significant differences were found in TEWL level, friction index, sebum content and density of dermis between melasma skin and normal surrounding skin (Figure 1).

Also melasma subtype (epidermal, dermal, or mixed) had no significant effect on any of these variables (Table 1).

There was no significant relation between age, skintype, location, and duration with Diffs separately.

Correlation between age and density of dermis was positive, Pearson correlation coefficient $=+0.354, \mathrm{P}=0.3$. Correlation between age and erythema was negative, Pearson correlation coefficient = $-0.313, \mathrm{P}=0.06$.

Although the relation between skintype and melasma subtype is not significant $(\mathrm{P}=0.11), 50 \%$ of patients with skintype 3 , and only $14.3 \%$ of those with skintype 4 have epidermal subtype.

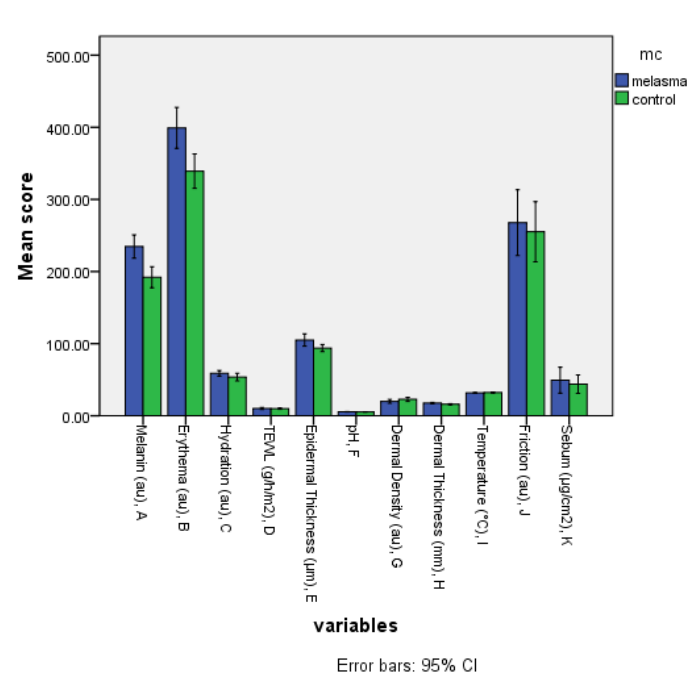

Figure 1: Biophysical characteristics of melasma compared to adjacent normal skin, $\mathrm{P}$-value $<0.05$ is significant, $\mathrm{A}: \mathrm{P}=0.001, \mathrm{~B}: \mathrm{P}$ $=0.001, \mathrm{C}: \mathrm{P}=0.037, \mathrm{D}: \mathrm{P}=0.850, \mathrm{E}: \mathrm{P}=0.002, \mathrm{~F}: \mathrm{P}=0.002, \mathrm{G}: \mathrm{P}$ $=0.136, \mathrm{H}: \mathrm{P}=0.001$, I: $\mathrm{P}=0.001, \mathrm{~J}: \mathrm{P}=0.521, \mathrm{~K}: \mathrm{P}=0.309$.

\section{Discussion}

In this study on 36 non-pregnant Iranian women, it was shown that the melasma skin had a higher melanin index, erythema index, SC hydration, $\mathrm{pH}$, dermal and epidermal thickness, and lower temperature compared to the normal adjacent skin, whereas the basal TEWL, sebum, friction index and dermal echo-density were not 
different. On the other hand, there was not any difference among three subtypes of melasma (epidermal, mixed, dermal) considering these biophysical parameters.

As the biophysical characteristics of the skin vary due to age, sex, season, etc. [8], it is very important to use the adjacent normal appearing skin as the control in the evaluation of these parameters in skin disorders [9].

It has been shown that black skin had significantly higher mean TEWL than white skin $[10,11]$. Blacks also have significantly less $\mathrm{pH}$ values than white subjects after application of tape strips [10] and $\mathrm{pH}$ is generally lower in black SC [11].

Dark skin has more cell layers in stratum corneum, greater electrical resistance, better intercellular cohesion, faster recovery after barrier damage and more TEWL in stripped skin [7]. A more resistant barrier is also displayed in dark skin [12].

\begin{tabular}{|c|c|c|c|}
\hline \multicolumn{4}{|l|}{ Melasma Subtype } \\
\hline Variables & Epidermal & Dermal & Mixed \\
\hline Melanin (a.u.) & $\begin{array}{ll}228.33 & \pm \\
45.37 & \end{array}$ & $238.35 \pm 45.47$ & $236.47 \pm 55.84$ \\
\hline Erythema (a.u.) & $\begin{array}{ll}427.99 & \pm \\
84.99 & \end{array}$ & $377.66 \pm 70.26$ & $396.08 \pm 95.32$ \\
\hline Hydration (a.u.) & $60.41 \pm 9.61$ & $61.86 \pm 11.92$ & $54.16 \pm 11.91$ \\
\hline TEWL $\left(\mathrm{g} / \mathrm{h} / \mathrm{m}^{2}\right)$ & $9.18 \pm 3.10$ & $9.45 \pm 4.26$ & $11.40 \pm 4.48$ \\
\hline Epidermal Thickness $(\mu \mathrm{m})$ & $96.20 \pm 21.35$ & $116.53 \pm 29.21$ & $99.45 \pm 16.48$ \\
\hline $\mathrm{pH}$ & $5.41 \pm 0.65$ & $5.75 \pm 0.40$ & $5.56 \pm 0.58$ \\
\hline Dermal density (a.u.) & $17.36 \pm 4.24$ & $21.23 \pm 7.80$ & $21.18 \pm 10.30$ \\
\hline Dermal Thickness (mm) & $1.78 \pm 0.23$ & $1.71 \pm 0.19$ & $1.78 \pm 0.43$ \\
\hline Temperature $\left({ }^{\circ} \mathrm{C}\right)$ & $32.10 \pm 1.11$ & $31.66 \pm 1.53$ & $31.28 \pm 1.97$ \\
\hline Friction (a.u.) & $\begin{array}{ll}241.40 & \pm \\
80.23 & \end{array}$ & $\begin{array}{l}294.31 \\
128.20\end{array} \quad \pm$ & $\begin{array}{l}264.82 \\
172.66\end{array}$ \\
\hline Sebum $\left(\mu \mathrm{g} / \mathrm{cm}^{2}\right)$ & $65.36 \pm 57.30$ & $28.92 \pm 24.41$ & $57.45 \pm 67.29$ \\
\hline
\end{tabular}

Table 1: Biophysical characteristics of skin in 3 subtypes of melasma. $(\mathrm{P}$-value $>0.05$ in all $)($ mean $\pm \mathrm{SD})$.

There is only one study comparing biophysical characteristics of melasma skin with normal surrounding skin in 16 Asian women. Our study recruited a higher number of patients (36) with different ethnic background. Melanin index, erythema index, and SC hydration were significantly higher in melasma skin in that study, which was similar to the findings of our study. TEWL was also higher in that report, but it didn't reach significance level [7].

Increased erythema index in melasma skin was reported in both studies. Vascular endothelial growth factor (VEGF) could have a direct influence on melanocyte behavior through its receptor on them [13]. More vascularity is clinically and histologically seen in melasma due to more upregulation of VEGF expression resulting the increase number of vessels; also, blood vessels or endothelial cells modified by UV radiation may release cytokines and soluble factors like plasminogen, which might be a possible cause of hyperpigmentation in melisma [13].
Epidermal changes are important in the activity of melanocytes and melanin production in melasma because there is a potential cross-talk between keratinocytes and melanocytes for pigmentation in response to stress to the barrier [14]. On the other hand, chronic UV radiation (which is the main pathogenic factor in melisma) causes downregulation of lipid metabolism-related genes so less synthesis of epidermal free fatty acids (FFA) and triglycerides occurs in melisma [7]. Also downregulation of several lipid metabolism-associated genes such as peroxisome proliferator-activated receptor alpha (PPARA) leads to barrier damage in melisma [7].

Basal TEWL was not different between melasma and normal skin in the present study. More TEWL after barrier damage and delayed barrier recovery rate were demonstrated in the previous report [7], which they were not assessed in our study.

Stratum corneum assessed in histologic samples was thinner (although not significantly) in melasma skin in the previous report [7], but the thickness of epidermis assessed by HFUS was higher in melasma skin in our study. The number and/or size of viable keratinocytes might have increased in melasma.

Some biophysical characteristics of melasma were evaluated for the first time in this study. Melasma skin was found more alkaline in our study. Melanosomes are acidic organelles and one important reason of the lower $\mathrm{pH}$ of SC in darkly pigmented subjects may be the transfer of additional and/or more acidified organelles from the melanocytic dendrites to the outer epidermis of neighboring keratinocytes [15].

Further studies are required to find the cause of alkaline skin in melasma.

Dermal echodensity and thickness was higher in melasma skin, so dermal changes may also be involved in the pathogenesis of melasma, even the epidermal subtype.

Skin surface was found cooler in melasma in this study, which is contradicting to the increased vascularity found in dermis in melasma skin.

Frictional index of melasma skin was not different in our study. Repeated frictional trauma against the skin is an important factor in the pathogenesis of some pigmentary dermatoses, such as frictional melanosis [16].

The influence of subtypes of melasma was not evaluated in the previous study. We could not find any difference in any of biophysical characteristics of skin among three subtypes of melasma (epidermal, mixed, and dermal). These findings emphasize that the level of melanin deposition in skin is not related to the changes in the biophysical properties of melasma skin.

The biophysical characteristics of skin in melasma have also been evaluated after treatment. Although the reduction in pigmentation is expected, the increase in erythema index is an interesting finding [17]. It is plausible that after reduction in melanin, the erythema in dermis becomes more evident; also, an increase in TEWL and SC hydration after treatment may be related to the epidermal damage caused by the retinoid present in the treatment [18].

Inter individual, ethnic and geographic differences may also contribute to the changes in melasma skin. So larger studies on melisma patients from different part of the world would be beneficial. 
Citation: Rahrovan S, Hasanzadeh H, Khodakarim S, Firooz A (2015) Biophysical Characteristics of Melasma Skin Comparing with the Perilesional Normal Skin and its Relation to the Melasma Subtype. Pigmentary Disorders 2: 222. doi:10.4172/2376-0427.1000222

Page 4 of 4

\section{References}

1. Young Kang H, Ortonne JP (2009) Melasma update. Actas Dermosifiliogr 100 Suppl 2: 110-113.

2. Sanchez NP, Pathak MA, Sato S, Fitzpatrick TB, Sanchez JL, et al. (1981) Melasma: a clinical, light microscopic, ultrastructural, and immunofluorescence study. J Am Acad Dermatol 4: 698-710.

3. Wu IB, Lambert C, Lotti TM, Hercogová J, Sintim-Damoa A, et al. (2012) Melasma. G Ital Dermatol Venereol 147: 413-418.

4. Passeron T (2013) Melasma pathogenesis and influencing factors - an overview of the latest research. J Eur Acad Dermatol Venereol 27 Suppl 1: 5-6.

5. Sheth VM, Pandya AG (2011) Melasma: a comprehensive update: part I. J Am Acad Dermatol 65: 689-697.

6. Torres-Álvarez B, Mesa-Garza IG, Castanedo-Cázares JP, FuentesAhumada C, Oros-Ovalle C, et al. (2011) Histochemical and immunohistochemical study in melasma: evidence of damage in the basal membrane. Am J Dermatopathol 33: 291-295.

7. Lee DJ, Lee J, Ha J, Park KC, Ortonne JP, et al. (2012) Defective barrier function in melasma skin. J Eur Acad Dermatol Venereol 26: 1533-1537.

8. Firooz A, Sadr B, Babakoohi S, Sarraf-Yazdy M, Fanian F, et al. (2012) Variation of biophysical parameters of the skin with age, gender, and body region. ScientificWorldJournal 2012: 386936.

9. Firooz A, Gorouhi F, Davari P, Atarod M, Hekmat S, et al. (2007) Comparison of hydration, sebum and $\mathrm{pH}$ values in clinically normal skin of patients with atopic dermatitis and healthy controls. Clin Exp Dermatol 32: 321-322

10. Berardesca E, Pirot F, Singh M, Maibach H (1998) Differences in stratum corneum $\mathrm{pH}$ gradient when comparing white Caucasian and black African-American skin. Br J Dermatol 139: 855-857.
11. Darlenski R, Fluhr JW (2012) Influence of skin type, race, sex, and anatomic location on epidermal barrier function. Clin Dermatol 30: 269-273.

12. Reed JT, Ghadially R, Elias PM (1995) Skin type, but neither race nor gender, influence epidermal permeability barrier function. Arch Dermatol 131: 1134-1138.

13. Kim EH, Kim YC, Lee ES, Kang HY (2007) The vascular characteristics of melasma. J Dermatol Sci 46: 111-116.

14. Elias PM, Menon G, Wetzel BK, Williams JJ (2009) Evidence that stress to the epidermal barrier influenced the development of pigmentation in humans. Pigment Cell Melanoma Res 22: 420-434.

15. Gunathilake R, Schurer NY, Shoo BA, Celli A, Hachem JP, et al. (2009) $\mathrm{pH}$-regulated mechanisms account for pigment-type differences in epidermal barrier function. J Invest Dermatol 129: 1719-1729.

16. Al-Aboosi M, Abalkhail A, Kasim O, Al-Khatib A, Qarqaz F, et al. (2004) Friction melanosis: a clinical, histologic, and ultrastructural study in Jordanian patients. Int J Dermatol 43: 261-264.

17. Chan R, Park KC, Lee MH, Lee ES, Chang SE,et al. (2008) A randomized controlled trial of the efficacy and safety of a fixed triple combination (fluocinolone acetonide $0.01 \%$, hydroquinone $4 \%$, tretinoin $0.05 \%$ ) compared with hydroquinone $4 \%$ cream in Asian patients with moderate to severe melasma. Br J Dermatol 159: 697-703.

18. Pratchyapruit W, Vashrangsi N, Sindhavananda J, Tagami H (2011) Instrumental analysis of the pattern of improvement and that of recurrence of melasma in Thai females treated with Kligman-Willis triple combination therapy: confirmation by using its two different formulae. Skin Res Technol 17: 226-233. 